\title{
Stéphane Chaudier, Proust et le langage religieux. La cathédrale profane
}

\section{Emanuele Kanceff}

\section{(2) OpenEdition}

1 Journals

\section{Edizione digitale}

URL: http://journals.openedition.org/studifrancesi/33572

DOI: 10.4000/studifrancesi.33572

ISSN: 2421-5856

\section{Editore}

Rosenberg \& Sellier

\section{Edizione cartacea}

Data di pubblicazione: 1 décembre 2005

Paginazione: 672-673

ISSN: 0039-2944

\section{Notizia bibliografica digitale}

Emanuele Kanceff, «Stéphane Chaudier, Proust et le langage religieux. La cathédrale profane», Studi Francesi [Online], 147 (XLX | III) | 2005, online dal 30 novembre 2015, consultato il 19 avril 2021. URL: http://journals.openedition.org/studifrancesi/33572; DOI: https://doi.org/10.4000/studifrancesi. 33572

Questo documento è stato generato automaticamente il 19 avril 2021.

\section{(c) $(1) \ominus$}

Studi Francesi è distribuita con Licenza Creative Commons Attribuzione - Non commerciale - Non opere derivate 4.0 Internazionale. 


\title{
Stéphane Chaudier, Proust et le langage religieux. La cathédrale profane
}

\author{
Emanuele Kanceff
}

\section{NOTIZIA}

STÉPHANE CHAUDIER, Proust et le langage religieux. La cathédrale profane, Paris, Honoré Champion Éditeur, 2004 («Recherches proustiennes»), pp. 549.

1 La parola "religioso" designa nello stesso tempo l'ambizione estetica del giovane Proust (l'A. si riferisce ad una lettera del 1895) e la sua incapacità di esprimere in modo più netto e personale la natura della sua vocazione di scrittore, sostiene Chaudier. Sarebbe dunque, in quel periodo, l'espressione dell'intima necessità di diventare artista $\mathrm{e}$ dell'imbarazzo che lo scrivente prova di fronte a tale intima necessità. Ma è possibile leggere Proust alla luce del "religioso" senza perdersi nei meandri di un'estetica spiritualista?

2 L'opera e lo stile dello scrittore testimoniano una vera passione per il religioso. Il testo, tuttavia, ricorre a vocaboli religiosi a proposito di soggetti quasi sempre profani. Non si può legare tali utilizzazioni verbali ad un'esperienza religiosa o spirituale. Invece, uno studio lessicologico del vocabolario religioso di Proust potrebbe mostrare come tale terminologia si dispiega in figure la cui ricorrenza e organizzazione producono un immaginario poetico.

3 Il linguaggio religioso testimonia il vivo interesse dello scrittore per le credenze e il suo rifiuto dell'autorità spirituale riconosciuta: sensibile alla passione religiosa che anima l'uomo, alla bellezza di tale esperienza, egli manifesta una incontenibile tendenza a pensare il mondo in termini presi a prestito dal campo giudaico e cristiano, talché la sua opera si nutre della paradossale tensione tra vocabolario religioso e soggetto profano. Per questo il vocabolario religioso è presente sopratutto dove non lo si cercherebbe: nei contesti ribelli a qualsiasi prospettiva sacra, nelle conversazioni mondane e frivole, nella descrizione di un bordello, nel ritratto di un diplomatico, 
nell'evocazione di una stazione ferroviaria. Il linguaggio religioso serve a Proust per costruire e smontare realtà come l'amore, la mondanità, l'arte, la fede, le molte credenze che lo scrittore analizza per scoprirne la coerenza e l'intima necessità, la bellezza e l'inettitudine. «La vocation proustienne - conclude l'A. - fait entendre le bruissement d'un langage dont Dieu s'est retiré. Sans nostalgie et sans culpabilité, l'œuvre dessine l'empreinte de ce Dieu qui s'est dérobé. Proust ne croit pas en lui; Dieu reste pourtant le modèle lointain, fascinant, de l'artiste créateur désireux d'exalter l'usage poétique et gratuit du style, appareil à représenter mais aussi à vivre». 